\title{
Metatranscriptomic analysis of prokaryotic communities active in sulfur and arsenic cycling in Mono Lake, California, USA
}

\author{
Christian F Edwardson ${ }^{1,2,3}$ and James T Hollibaugh ${ }^{1}$ \\ ${ }^{1}$ Department of Marine Sciences, University of Georgia, Athens, GA, USA and ${ }^{2}$ Department of Microbiology, \\ University of Georgia, Athens, GA, USA
}

\begin{abstract}
This study evaluates the transcriptionally active, dissimilatory sulfur- and arsenic-cycling components of the microbial community in alkaline, hypersaline Mono Lake, CA, USA. We sampled five depths spanning the redox gradient $(10,15,18,25$ and $31 \mathrm{~m})$ during maximum thermal stratification. We used custom databases to identify transcripts of genes encoding complex iron-sulfur molybdoenzyme (CISM) proteins, with a focus on arsenic (arrA, aioA and arxA) and sulfur cycling (dsrA, aprA and soxB), and assigned them to taxonomic bins. We also report on the distribution of transcripts related to the ars arsenic detoxification pathway. Transcripts from detoxification pathways were not abundant in oxic surface waters $(10 \mathrm{~m})$. Arsenic cycling in the suboxic and microaerophilic zones of the water column (15 and $18 \mathrm{~m})$ was dominated by arsenite-oxidizing members of the Gammaproteobacteria most closely affiliated with Thioalkalivibrio and Halomonas, transcribing arxA. We observed a transition to arsenate-reducing bacteria belonging to the Deltaproteobacteria and Firmicutes transcribing arsenate reductase (arrA) in anoxic bottom waters of the lake (25 and $31 \mathrm{~m})$. Sulfur cycling at 15 and $18 \mathrm{~m}$ was dominated by Gammaproteobacteria (Thioalkalivibrio and Thioalkalimicrobium) oxidizing reduced S species, with a transition to sulfate-reducing Deltaproteobacteria at 25 and $31 \mathrm{~m}$. Genes related to arsenic and sulfur oxidation from Thioalkalivibrio were more highly transcribed at $15 \mathrm{~m}$ relative to other depths. Our data highlight the importance of Thioalkalivibrio to arsenic and sulfur biogeochemistry in Mono Lake and identify new taxa that appear capable of transforming arsenic.

The ISME Journal (2017) 11, 2195-2208; doi:10.1038/ismej.2017.80; published online 26 May 2017
\end{abstract}

\section{Introduction}

Redox reactions mediated by microbes are important to the geochemical cycles of both sulfur and arsenic. Historically, sulfur and arsenic have been studied together due to their co-occurrence in the minerals arsenopyrite, orpiment and realgar (Lengke et al., 2009). Soluble arsenic-sulfur oxyanions, known as thioarsenic compounds, have been identified in the environment where they play an important role in arsenic geochemistry, especially in sulfidic and alkaline waters (Hollibaugh et al., 2005; PlanerFriedrich et al., 2007; Fisher et al., 2008b). Thioarsenic compounds have been shown to decompose rapidly in oxic environments (Hollibaugh et al., 2005; Planer-Friedrich et al., 2009), and laboratory experiments (Fisher et al., 2008b; Edwardson et al., 2014) suggest that bacteria capable of oxidizing

Correspondence: JT Hollibaugh, Department of Marine Sciences, University of Georgia, Athens, GA 30602, USA.

E-mail: aquadoc@uga.edu

${ }^{3}$ Present address: Shedd Aquarium, Chicago, IL, USA.

Received 24 August 2016; revised 4 April 2017; accepted 18 April 2017; published online 26 May 2017 reduced sulfur species (sulfide, thiosulfate and so on) are involved.

The diversity, ecology and physiology of microorganisms catalyzing the transformation of sulfur compounds such as sulfide, elemental sulfur, sulfate and thiosulfate are well known (Kelly et al., 1997; Muyzer and Stams, 2008), and the role of bacteria in arsenic transformations is also well established. Both oxidative (Oremland et al., 2002; Hamamura et al., 2009) and reductive (Saltikov and Newman, 2003; Hoeft et al., 2004) pathways have been characterized (Oremland and Stolz, 2003; Silver and Phung, 2005). These energy-yielding redox transformations occur in a few lineages of prokaryotes (mainly Firmicutes and Proteobacteria) in contrast to arsenic detoxification transformations that are ubiquitous in both prokaryotes and eukaryotes (Rosen, 2002). More recently, links between the microbial geochemistry of sulfur and arsenic have been investigated, especially in soda lakes and alkaline thermal springs (Hoeft et al., 2004; Hollibaugh et al., 2005; Fisher et al., 2008b; Planer-Friedrich et al., 2009; Edwardson et al., 2014). One such environment is Mono Lake, a hypersaline soda lake in California, USA. Mono Lake contains elevated levels of arsenic 
$(>200 \mu \mathrm{M})$ and sulfide concentrations can be high ( $>1 \mathrm{~mm}$ ), especially in anoxic bottom waters following prolonged stratification. These conditions lead to the formation of significant concentrations of thioarsenic compounds in these waters (Hollibaugh et al., 2005) where they are stable due to the elevated $\mathrm{pH}$ of the lake (Hollibaugh et al., 2005; Planer-Friedrich et al., 2010).

The enzymes involved in dissimilatory transformations of arsenic are well established (Silver and Phung, 2005). Arsenate respiratory reductase (ArrA; Saltikov and Newman, 2003), arsenite oxidase (AioA; Inskeep et al., 2007; Lett et al., 2012) and a more recently identified alternate arsenite oxidase (ArxA; Zargar et al., 2010, 2012) are all members of the complex iron-sulfur molybdoenzyme (CISM) family (van Lis et al., 2013), and assays to examine the genes for these enzymes have been established (Malasarn et al., 2004; Kulp et al., 2006; Zargar et al., 2012). Microbial enzymes used for detoxification purposes include those encoded by the the ars operon (Rosen, 2002) and by related proteins such as UspA (Weiss et al., 2009) and Acr3 (Fu et al., 2009).

Molecular markers for both oxidative and reductive pathways of sulfur transformations include the sox genes, encoding the thiosulfate/sulfur oxidation enzyme system (Meyer et al., 2007), the reversible dissimilatory sulfite reductase (dsrAB; Muller et al., 2015), and adenosine-5'-phosphosulfate (APS) reductase (aprBA; Meyer and Kuever, 2007a). APS reductase catalyzes the transformation of APS to sulfite, which is a key step in the pathways of both sulfate reduction and sulfite oxidation to sulfate (Meyer and Kuever, 2007b).

The use of environmental transcripts to identify putatively active microbes and their contribution to biogeochemical cycling in various environments has provided important insights into microbial carbon cycling (Poretsky et al., 2010; Satinsky et al., 2014), the nitrogen cycle (Hollibaugh et al., 2014; Hilton et al., 2015), and the sulfur cycle (Canfield et al., 2010; Stewart et al., 2011). Here, high throughput sequencing of environmental mRNA (metatranscriptomics) was used to gain further insights into the microbial communities responsible for arsenic and sulfur cycling in Mono Lake, CA, USA. We identified transcripts of key enzymes mediating the oxidative and reductive pathways of the sulfur and arsenic cycles and determined their taxonomic affiliations and vertical distributions. This allowed us to examine variation with depth and redox potential of microbially mediated arsenic and sulfur transformations. In addition, our analysis revealed novel lineages of microorganisms potentially involved in arsenic and sulfur cycling in Mono Lake.

\section{Materials and methods}

Field site and sampling

We sampled at Station 6 (41 m water column depth) in the southern basin of Mono Lake in July, 2012. We obtained vertical profiles of Conductivity, Temperature, and Depth/pressure (CTD), as well as photosynthetically active radiation (PAR), in vivo fluorescence, dissolved oxygen and beam attenuation on July 12 using an SBE19 Seacat CTD equipped with ancillary sensors. We then collected water samples from depths of $10,15,18,25$ and $31 \mathrm{~m}$, chosen to sample the major redox zones of the lake, using a Niskin sampler deployed on a rope as described previously (Hollibaugh et al., 2005). Samples for arsenic speciation and sulfide concentration were collected directly from the Niskin sampler and preserved in the field (see Supplementary Methods for details).

\section{Nucleic acid sampling and processing}

Samples for RNA analysis were collected by pumping water from $31 \mathrm{~m}$ on July 12 and from $10-25 \mathrm{~m}$ on July 13. Duplicate samples of total particulate RNA $(\sim 0.5-2 \mathrm{l})$ were collected on $142 \mathrm{~mm}$ diameter, $0.2 \mu \mathrm{m}$ pore-size Supor membrane filters. The filters were placed in $15 \mathrm{ml}$ polypropylene centrifuge tubes and immediately frozen in liquid nitrogen, then transported to the laboratory where they were stored at $-80{ }^{\circ} \mathrm{C}$ until extracted. The elapsed time from beginning the filtration at a given depth until the filter was placed in liquid nitrogen was $<15 \mathrm{~min}$. Total RNA was extracted from particles retained by the filters using bead beating and RNEasy Mini Kits (Gifford et al., 2011 and Supplementary Methods), with internal standards added as described previously (Satinsky et al., 2013).

Water for 16S ribosomal RNA (rRNA) gene analysis and synthesis of subtractive hybridization probes was collected from 5l Niskin bottles into foil-wrapped HDPE bottles with minimal head space and stored in an insulated cooler on ice until processed further. Water was filtered within $8 \mathrm{~h}$ of collection through SterivexGV $0.22 \mu \mathrm{m}$ pore-size cartridge filters (EMD Millipore, Billerica, MA, USA) using a peristaltic pump. DNA was extracted from the filters using a lysozyme-proteinase $\mathrm{K}$ digestion followed by phenol-chloroform extraction as described previously (Kalanetra et al., 2009). Quantitative PCR (qPCR) of Bacteria 16S rRNA genes in this DNA (Kalanetra et al., 2009) was used to estimate the depth distribution of Bacteria.

\section{Metatranscriptomics}

Libraries for metatranscriptomics analysis were prepared from total RNA using a protocol modified from Stewart et al., (2010). Briefly, rRNA was depleted using probes synthesized by PCR from DNA collected at each sampling depth (Supplementary Methods). Messenger RNA was amplified from rRNA-depleted total RNA using random hexamer primers, then double-stranded cDNA was prepared using reverse transcriptase and second strand synthesis kits. Libraries ( 225 bp insert) were prepared using Illumina TruSeq technology. Samples were pooled and run on one lane of $150 \times 2$ 
Illumina HiSeq 2500 Rapid Run at HudsonAlpha Genomic Services. Reads have been deposited in the NCBI SRA under accession number SRP068308 (Bioproject PRJNA308451).

\section{Bioinformatics}

Sequences were processed using a custom pipeline described in more detail in Supplementary Methods. Briefly, paired ends were joined, the ends of combined reads were trimmed to remove low quality base calls, then ribosomal RNA reads and internal standards were counted and removed from the data set. Sequences that remained were annotated by alignment to the NCBI RefSeq database using RapSearch2, retaining only top hits with bit scores $>40$ and e-values $<10^{-5}$. Taxonomy was assigned and absolute abundances (transcripts $\mathrm{L}^{-1}$ ) were calculated using counts of internal standards as described previously (Satinsky et al., 2013).

\section{Identification of complex iron-sulfur molybdoenzyme transcripts}

A custom database of 110 amino acid sequences from the catalytic subunit of representative complex iron-sulfur molybdoenzymes (CISM, Supplementary Table S1) was prepared using sequences from various references (Rothery et al., 2008; Schoepp-Cothenet et al., 2012; Denton et al., 2013; Grimaldi et al., 2013). The sequences were downloaded from NCBI and edited in Geneious (Kearse et al., 2012). BLASTx (Altschul et al., 1990) was used to query all reads from each sample against this database. All hits with bit scores $>40$ were retained (Gifford et al., 2011). Reads that had hits to the custom database were matched with their respective entry in the RefSeq database using RapSearch2. If there was no RapSearch2 hit, BLASTx was used to search against the RefSeq database.

\section{Identification of sulfur cycling transcripts}

Amino acid sequences of proteins involved in oxidative and reductive pathways of microbial sulfur metabolism (Supplementary Table S2) were obtained using a text search of the UniRef90 database (Suzek et al., 2015). Additional sequences for some proteins (AprBA, DsrAB, Sat, SorAB and SoxABCDXYZ; Meyer et al., 2007; Meyer and Kuever, 2007a, c; Frigaard and Dahl, 2008; Loy et al., 2009; Mori et al., 2010) were obtained from GenBank and RefSeq. Sequences were clustered at 90\% identity with CD-HIT (Li and Godzik, 2006). All reads from each depth were searched against this database using BLASTx, and then processed as described above for the CISM database.

\section{Results}

Chemical characteristics of sampling depths

We sampled Mono Lake Station 6, the site of many of the previous microbiological studies of the lake, at five discrete depths $(10,15,18,25$ and $31 \mathrm{~m})$ selected based on the chemical profile of the lake at the time of sampling (Figure 1). The lake had been stratified for $>1$ year when sampled. The epilimnion is characterized by the highest temperatures $\left(>15^{\circ} \mathrm{C}\right)$, highest irradiance, highest dissolved oxygen concentrations and is subject to intense grazing by brine shrimp, Artemia monica (Jellison and Melack, 1993), which may have contributed to the low abundance of Bacteria there as indicated by quantitative PCR (Figure 1) and direct counts (LeCleir et al., unpublished data). We sampled the base of the epilimnion $(10 \mathrm{~m})$, the base of the oxycline $(15 \mathrm{~m})$, near the base of the thermocline $(18 \mathrm{~m})$ and in the anoxic hypolimnion (25 and $31 \mathrm{~m}$ ). The dissolved oxygen concentration at $15 \mathrm{~m}$ was $0.83 \mathrm{mg} \mathrm{l}^{-1}$ and decreased to the instrument's limit of detection $\left(0.68 \mathrm{mgl}^{-1}\right)$ at $15.8 \mathrm{~m}$, thus the $15 \mathrm{~m}$ sample is considered to be suboxic. The concentrations of sulfide, arsenate, arsenite and thioarsenic compounds varied with

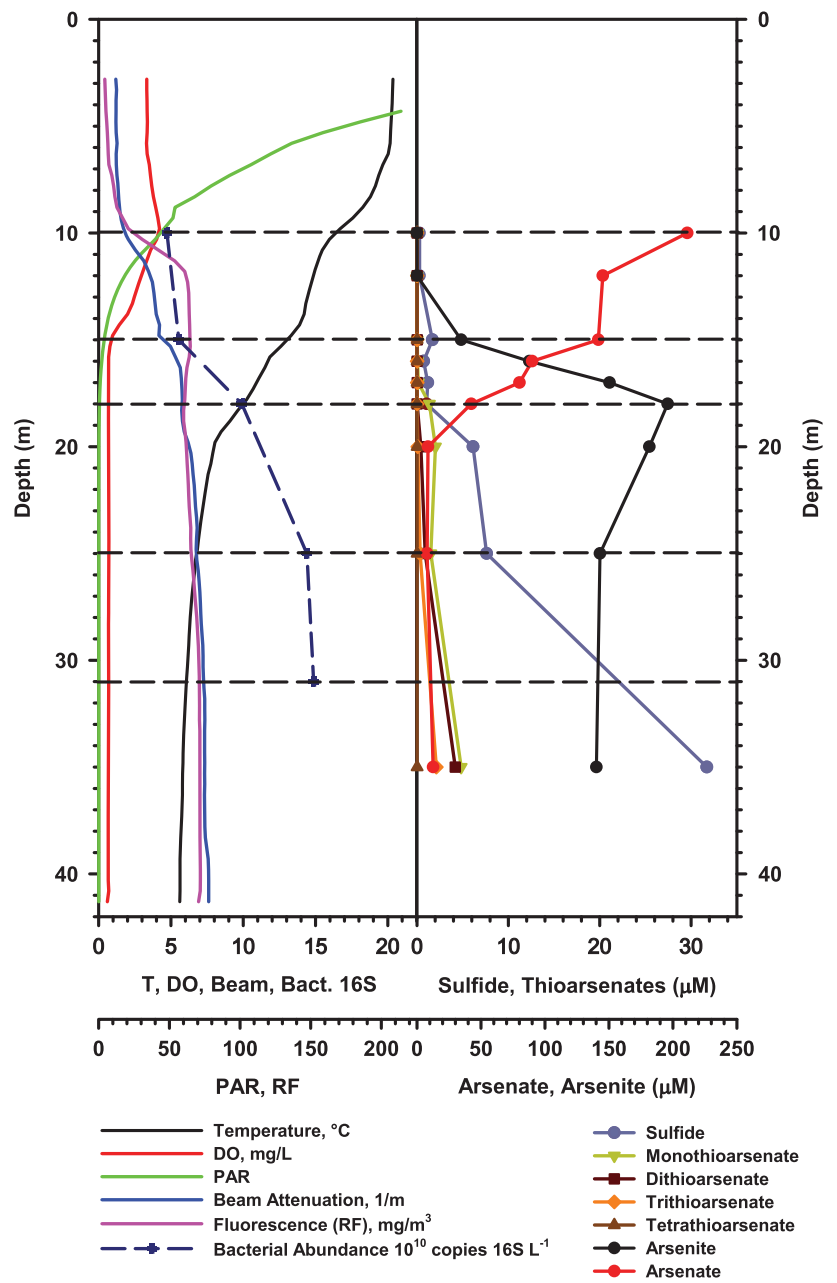

Figure 1 Vertical distribution of biogeochemical variables at Mono Lake Station 6, 12 July 2012. Metatranscriptome sampling depths are indicated by horizontal dashed lines. As, arsenic; Bact., Bacteria; DO, dissolved oxygen; PAR, photosynthetically active radiation; RF, relative fluorescence; S, sulfur; 16S, 16S ribosomal rRNA gene. 
depth. The $10 \mathrm{~m}$ sample was dominated by the oxyanion arsenate (99.9\% of arsenic, $211 \mu \mathrm{M})$. The 15 and $18 \mathrm{~m}$ samples were from the redox transition zone where arsenic speciation shifts from arsenate (15 m: $80.3 \%, 142 \mu \mathrm{M})$ to arsenite (18 m: 95\%, $196 \mu \mathrm{M})$. Trace quantities of thioarsenates were present at these depths. The anoxic hypolimnion was sampled at 25 and $31 \mathrm{~m}$. Sulfide appears at these depths $(6-30 \mu \mathrm{M})$ coincident with a decrease in arsenite concentration (from 196 to $140 \mu \mathrm{M}$ ), and formation of thioarsenic compounds (1-12 $\mu \mathrm{M})$. Sulfide and thioarsenic concentrations were much lower in July 2012 than recorded in August 2002, which followed 7 years of meromixis and when bottom water sulfide concentrations were $>2 \mathrm{~mm}$ (Hollibaugh et al., 2005). Although not measured at the time of sampling, sulfate concentration remains generally constant in the lake at $\sim 100 \mathrm{~mm}$ throughout the water column (Oremland et al., 2000).

\section{Overview of the metatranscriptome}

We obtained 115 million overlapping cDNA reads, with an average read length of 241 nt. Fewer than $1.1 \%$ of the transcripts in any sample were from Archaea or viruses, while Eukaryotes contributed 19-41\% (Table 1). Twenty-five to forty-seven percent (average $37 \%$ ) of non-rRNA reads had Rapsearch2 hits to the RefSeq database. Of these potentially protein coding reads, 58-79\% were classified as originating from bacteria (see Table 1). The most abundant ( $>1 \%$ relative abundance) bacterial genera in Mono Lake at the time of sampling were affiliated with the Proteobacteria and Firmicutes phyla (Figure 2); especially at 15-31 m. Transcripts assigned to members of the sulfur-oxidizing bacteria genera Thioalkalivibrio and Thioalkalimicrobium were especially abundant. A literature search to identify bacterial genera with the potential to perform arsenic and sulfur redox transformations (Canfield et al., 2010; Amend et al., 2014; Sorokin et al., 2015) revealed that almost half $(27 / 57)$ of the most abundant genera we identified contain strains with known capability for dissimilatory sulfur and arsenic metabolism (Figure 2).

\section{Arsenic and sulfur redox activity}

The concentration of transcripts, including CISM genes, was low at $10 \mathrm{~m}$ (Figure 3), paralleling the abundance of Bacteria (Figure 1), so our detailed analyses focused on of metatranscriptomes from $15 \mathrm{~m}$ and below. At $15 \mathrm{~m}$, the alternate arsenite oxidase $(\operatorname{arx} A)$ was the most abundant CISM transcript. The abundance of $\operatorname{arx} A$ transcripts was lower in samples from 18, 25 and $31 \mathrm{~m}$, with an increase in abundance of transcripts encoding arsenate reductase, with arsenite oxidation shifting to arsenate reduction as the dominant arsenic transformation. The canonical arsenite oxidase (aioA) was detected at very low abundance at all depths $(0,7.1,3.1,5.2$

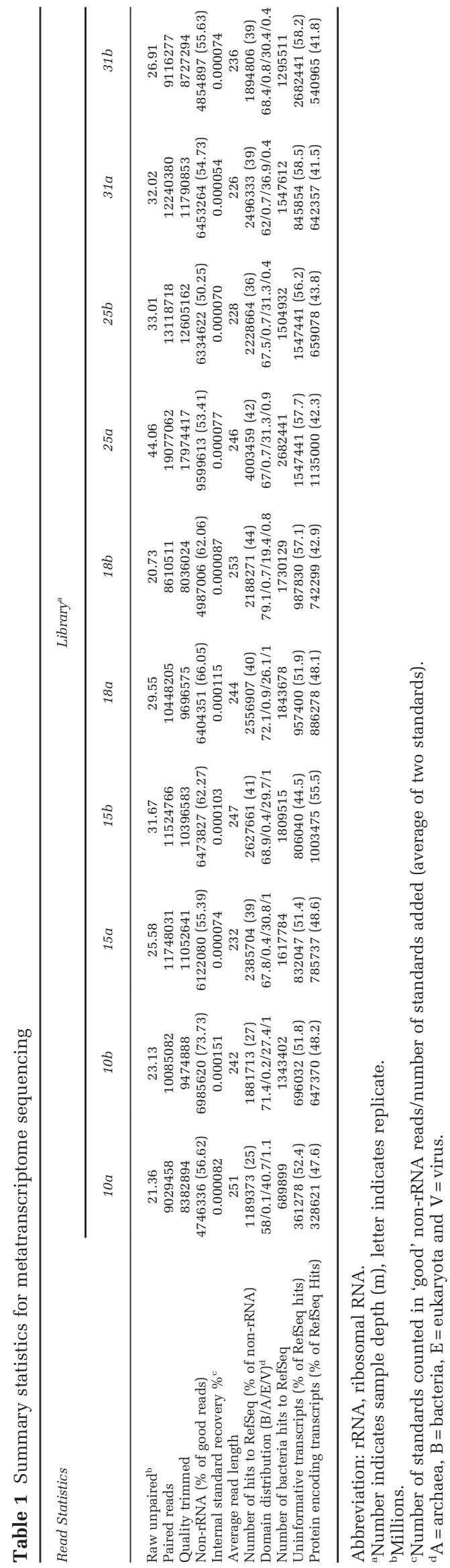


Relative Abundance (\%)

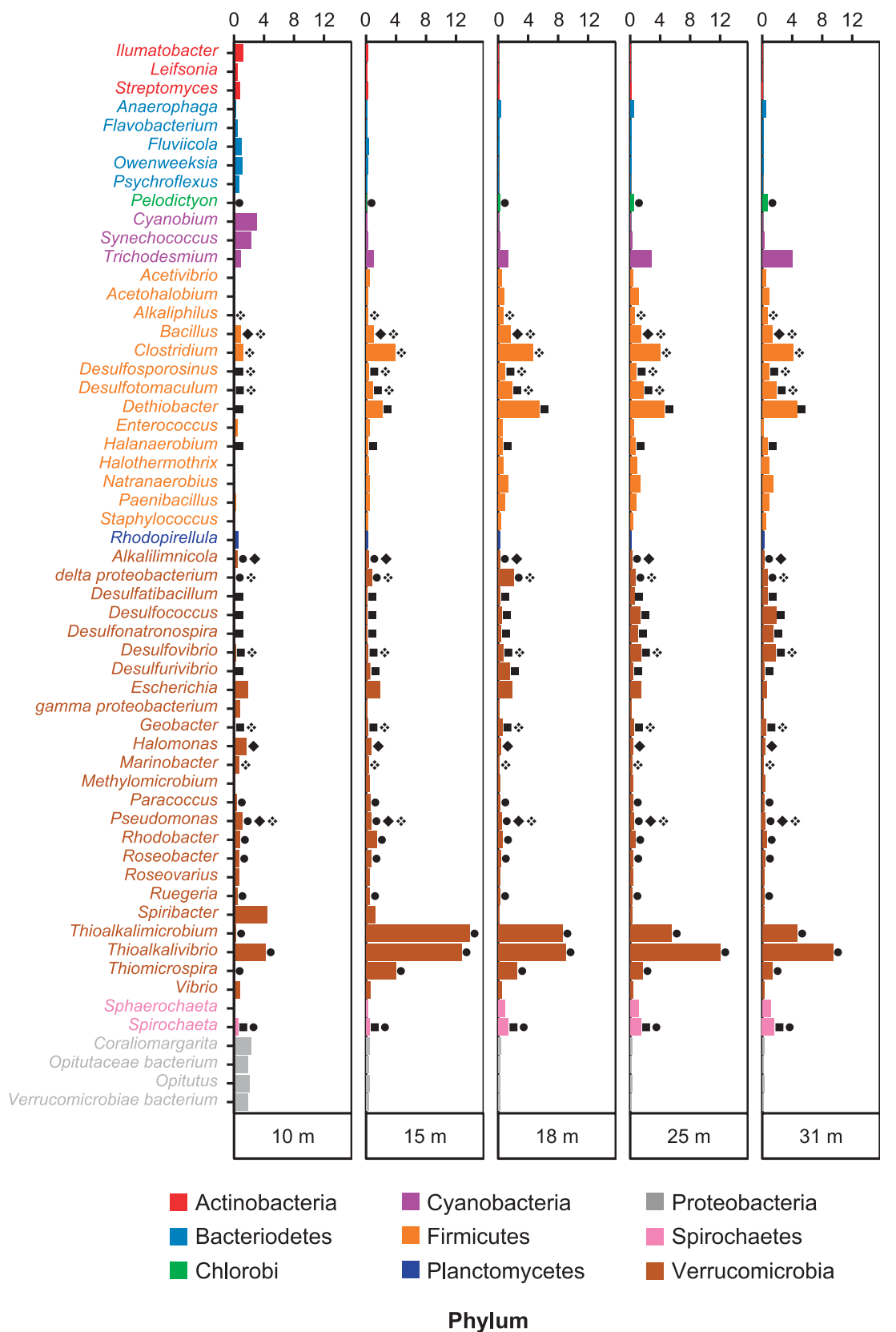

Figure 2 Taxonomic affiliations of transcripts recovered from 5 depths in the water column of Mono Lake, CA, USA. Relative abundance of transcripts (mean of 2 metatranscriptomes) assigned to individual genera is shown by the length of the bar opposite the taxonomic designation. Symbols next to bars indicate genera containing isolates known to perform the following arsenic and sulfur transformations: sulfur oxidation, circle; sulfate reduction, square; arsenite oxidation, hatched diamond; arsenate reduction, solid diamond.

and $2.3 \times 10^{6}$ copies per litre at 10,15, 18, 25 and $31 \mathrm{~m}$; respectively). In addition to arsenic redox enzymes, the most abundant CISM transcripts recruited to open reading frames annotated as different types of formate dehydrogenases ( $f d h A$, $f d h N$ and $f d n G$ ).

A closer examination of the taxonomic affiliation of $\operatorname{arx} A$ and $\operatorname{arr} A$ transcripts (Supplementary Figure S1) showed that the $\operatorname{arx} A$ transcripts were dominated by Thioalkalivibrio $(47-51 \%$ relative abundance) and Halomonas (25-39\%), with transcripts most similar to genes from Thioalkalivibrio nitratireducens, Halomonas boliviensis and Halomonas sp. A3H3. The taxonomic affiliations of arrA transcripts were more diverse, with representatives from at least 7 phyla. Dominant bacterial genera include Desulfurispirillum (Phylum Chrysiogenetes), Desulfitobacterium and Desulfosporosinus (Phylum Firmicutes), Aeromonas, Ferrimonas and Thioalkalivibrio (Class Gammaproteobacteria). 


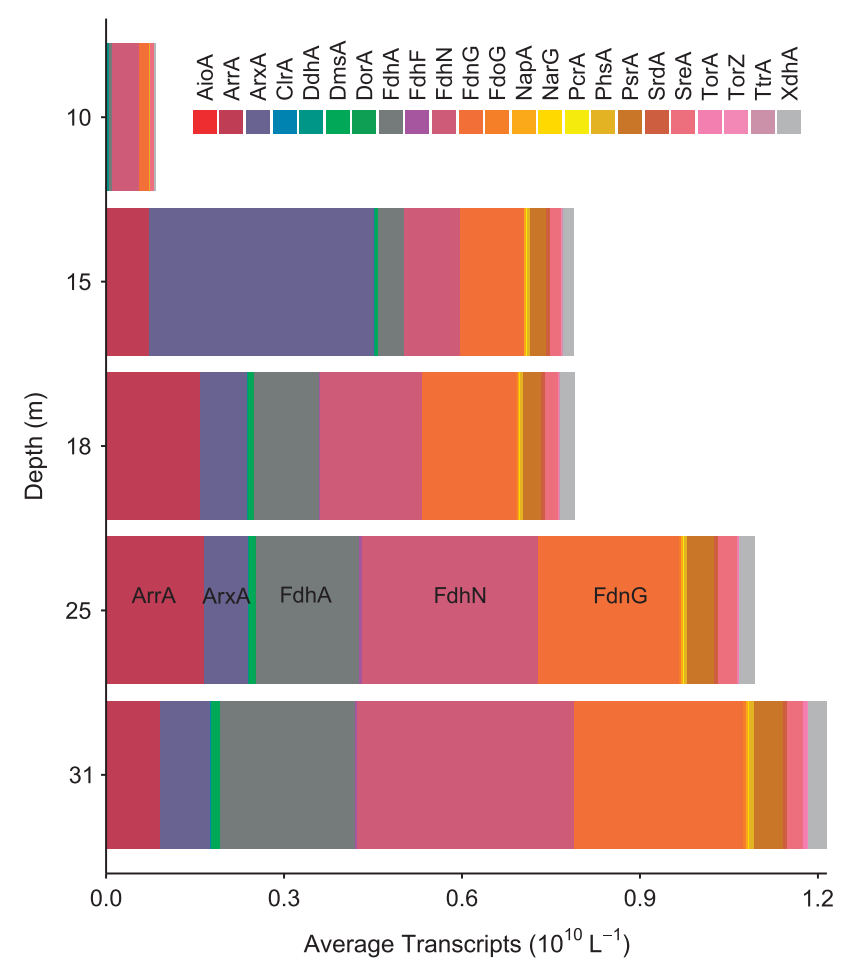

Figure 3 Average abundance (transcripts per litre) of hits to the complex iron-sulfur molybdoenzyme (CISM) custom database by depth in the water column of Mono Lake, CA, USA. Abbreviations of CISM protein names are: AioA, arsenite oxidase; ArrA, arsenate reductase; ArxA, anaerobic arsenite oxidase; ClrA, chlorate reductase; DdhA, dimethylsulfide dehydrogenase; DmsA, membranous DMSO reductase; DorA, DMSO reductase; FdhA, formate dehydrogenase subunit alpha; $\mathrm{FdhF}$, formate dehydrogenase-H; $\mathrm{FdhN}$, formate dehydrogenase; FdnG, NAD-dependent formate dehydrogenase; FdoG, formate dehydrogenase-O; NapA, periplasmic nitrate reductase; NarG, membrane-bound nitrate reductase; PcrA, perchlorate reductase; PhsA, polysulfide/thiosulfate reductase; PsrA, polysulfide/thiosulfate reductase; SerA, selenate reductase; SrdA, selenate reductase; SreA, sulfur reductase; TorA, TMAO reductase; TorZ, TMAO reductase (System III); TtrA, tetrathionate reductase; XdhA, xanthine dehydrogenase.

A BLASTp search against the NCBI database of the amino acid consensus sequences of assemblies yielding full-length $\operatorname{arr} A$ and $\operatorname{arx} A$ sequences (Figure 4) showed that the ArrA sequence (PROKKA_00186) was most closely related to Halarsenibacter silvermanii (59\% AA identity), a strain isolated from nearby Searles Lake (Blum et al., 2009), and Natranaerobius thermophilus (55\% AA identity), a haloalkalithermophile isolated from Wadi An Natrun, a soda lake in Egypt (Mesbah et al., 2007). The ArxA sequence (PROKKA_00030) was most closely related to Oceanospirillales bacteria including Nitrincola lacisaponensis and Halomonas strains (71-73\% AA identity). In addition, we detected transcripts related to arsenic resistance enzymes (Supplementary Figure S2) with increasing abundance to $25 \mathrm{~m}$, corresponding to the increase in arsenite concentration. The abundance of these transcripts was an order of magnitude lower than $\operatorname{arx} A$ and $\operatorname{arr} A$.
Sulfur redox cycling

The vertical distribution by taxon of transcripts that were assigned to genes in sulfur metabolism pathways (aprA, dsrA and soxB; Supplementary Figure S3) was similar to that of genes from the arsenic metabolism pathways. Transcripts in samples from $15 \mathrm{~m}$ were mostly affiliated with Gammaand Deltaproteobacteria (38-95\% and $12-15 \%$ respectively), with taxonomic assignments for aprA and $d s r A$ transcripts dominated by Thioalkalivibrio (Supplementary Figure S4, 65 and 35\% respectively). sox transcripts were most abundant at $15 \mathrm{~m}$ (Supplementary Figure S3) and Supplementary Figure S4 shows that $66 \%$ of soxB transcripts were most similar to genes from Thioalkalimicrobium, although transcripts most similar to genes from Thioalkalivibrio were also abundant (27\%). The abundance of $\operatorname{sox} B$ transcripts decreased with depth, whereas transcripts from $d s r A$ and aprA increased with depth. aprA transcripts from Deltaproteobacteria were present at $15 \mathrm{~m}$, but they increased in relative abundance at $18 \mathrm{~m}(12-65 \%)$ and the population was dominated by sequences most similar to genes in Deltaproteobacteria strain MLMS-1 (Supplementary Figure S4). aprA transcripts from 25 and $31 \mathrm{~m}$ were most similar to proteins from the Deltaproteobacteria Desulfatibacillum, Desulfococcus, Desulfonatronospira, and Desulfovibrio (Supplementary Figure S4, total 63\% and $78 \%$ relative abundance, respectively). Sequences most similar to genes from these organisms also contributed to the $d s r A$ transcript pool (17 and $23 \%$ ); however, the $d s r A$ transcript pool contained more reads affiliated with the sulfate-reducing Clostridia, including Desulfotomaculum, Natranaerobius, Desulfurispora and Dethiobacter $(21 \%$ at $25 \mathrm{~m}$ and $18 \%$ at $31 \mathrm{~m}$ ). The proportion of $d s r A$ transcripts affiliated with unclassified Thermoplasmatales Archaea increased with depth (15 m: 4\%, $18 \mathrm{~m}$ : 9\%, $25 \mathrm{~m}: 16 \%$ and $31 \mathrm{~m}: 14 \%$ ). dsrA transcripts from $15 \mathrm{~m}$ contained sequences most similar to genes from Clostridia (23\%) and Deltaproteobacteria (15\%) as well as from Gammaproteobacteria (38\%), but as depth increased, the contribution of sequences most similar to Gammaproteobacteria genes decreased (10 at $18 \mathrm{~m}$ to $2 \%$ at $31 \mathrm{~m}$ ).

More careful phylogenetic analysis revealed that the custom database search recruited paralogous sequences of a $4 \mathrm{Fe}-4 \mathrm{~S}$ ferredoxin of unknown function, but possibly an assimilatory sulfite reductase, most similar to genes from the Firmicutes and Thermoplasmatales Archaea. Although these prokaryotes likely contribute to sulfur cycling in the lake, it is unclear if they can gain energy from the reduction of sulfur compounds or if they contain the dissimilatory sulfite reductase enzyme complex. All sequences that contributed $>1 \%$ of the $d s r A$ transcripts at every depth are members of either the oxidative ('reverse') group, and most similar to genes from Thioalkalivibrio $(35 \%$ at $15 \mathrm{~m})$ or the Deltaproteobacteria orders Desulfovibrionales 

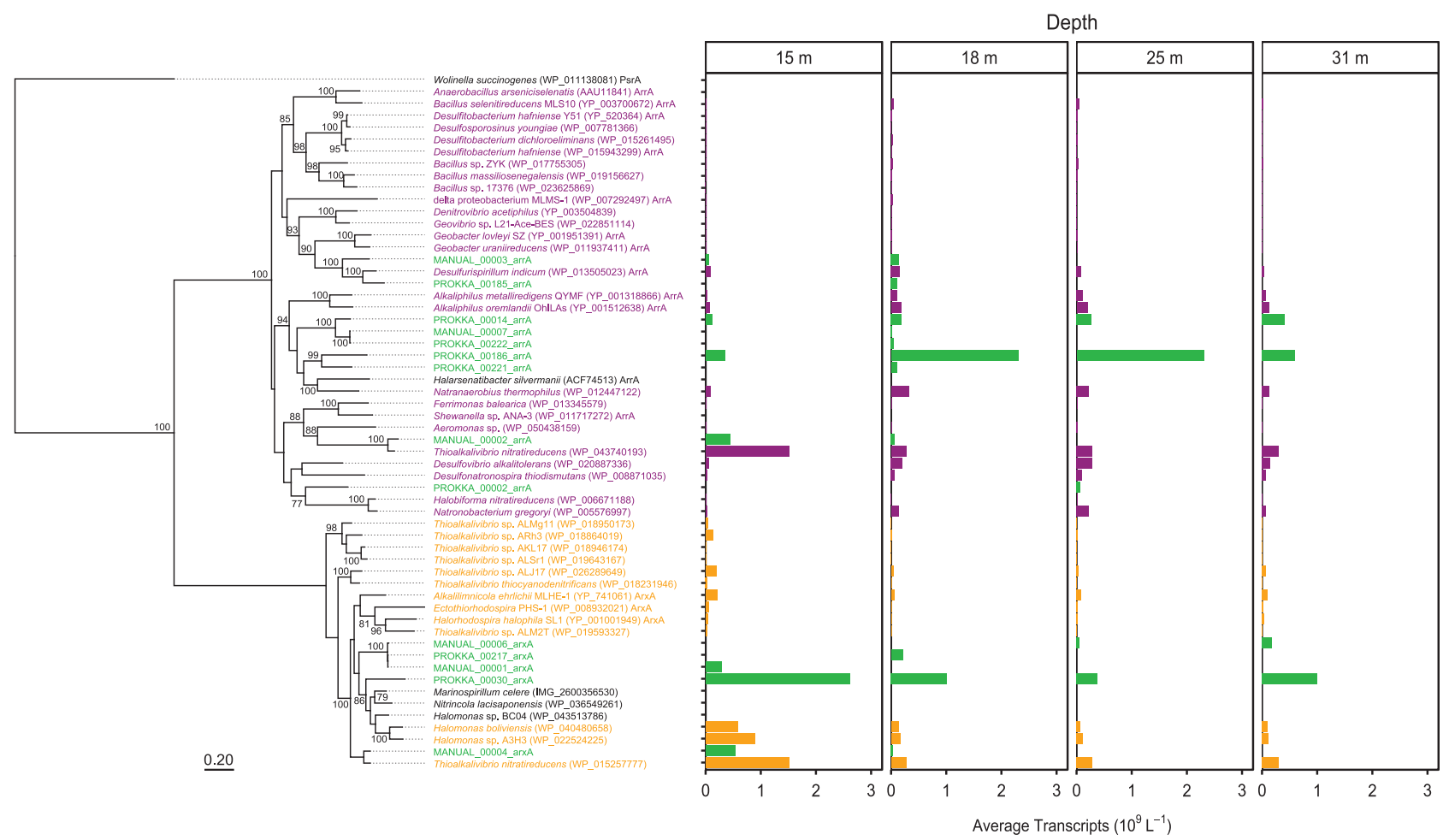

Figure 4 Maximum likelihood tree of known arsenate reductase (ArrA) and arsenite oxidase (ArxA) proteins (indicated as such in the tree) along with proteins found in reference genomes and representative (90\% identity cluster) inferred amino acid sequences of open reading frames found in contigs assembled from Mono Lake transcripts (green). Hits to reference proteins (ArrA, purple; ArxA, orange) are indicated by organism and RefSeq accession number. Reference sequences from organisms known to reduce arsenate or oxidize arsenite are indicated with ArrA and ArxA. Wolinella succinogenes polysulfide reductase (PsrA) was used as the outgroup. The LG+I+G model was used and bootstrap support (100 replicates) $>75 \%$ is shown.

(25 m: 14\%, $31 \mathrm{m:} 20 \%$ ) and Desulfobacterales (25 m: 13\%, $31 \mathrm{m:}$ 15\%). Two aprA consensus sequences: PROKKA_00232, most closely related to genes from Deltaproteobacteria strain MLMS-1 (95\% AA identity); and PROKKA_00196, most closely related to genes from Thioalkalivibrio nitratireducens (94\% AA identity), were abundant in assemblies from 15 and $18 \mathrm{~m}$. These transcripts were also abundant at $25 \mathrm{~m}$, as were transcripts related to five genes from sulfate-reducing Deltaproteobacteria (Supplementary Figure S5), highlighting the transition between sulfide oxidation and sulfate reduction between 18 and $25 \mathrm{~m}$. This parallels the transition from transcripts related to arsenite oxidation to transcripts involved in arsenate reduction at these depths. Transcripts of $d s r A$ displayed an almost identical trend (Figure 5). A general trend in the distribution of transcripts from sulfur-cycling genes is a shift from transcripts of sulfur oxidation genes most closely related to Desulfurivibrio alkaliphilus and strain MLMS-1 at 15 and $18 \mathrm{~m}$ to transcripts most similar to genes from the sulfate-reducing Desulfovibrionales group (Desulfovibrio and Desulfonatronospira thiodismutans) at greater depths. The Desulfobulbaceae (including MLMS-1 and Desulfurivibrio) are known sulfide oxidizers (Hoeft et al., 2004; Hollibaugh et al., 2006; Pfeffer et al., 2012), thus, sulfide oxidation occurs at $15-18 \mathrm{~m}$, with a switch to sulfate reduction at 25 and $31 \mathrm{~m}$. This is consistent with previous rate measurements (Oremland et al., 2000).

\section{Analysis of transcription by Thioalkalivibrio}

We performed additional analyses of transcripts in the top genome bin, Thioalkalivibrio nitratireducens, due to their significance in both arsenic and sulfur cycling pathways. All hits from each depth that were assigned to the Thioalkalivibrio taxonomic bin were aligned to the $T$. nitratireducens (Tnat) genome by BLASTx against all Tnat protein sequences. Our assumption was that transcripts binning to genes from Thioalkalivibrio would have homologs in the Tnat genome. The goal of this exercise was to capture the functional diversity of the Thioalkalivibrio genus, since it is unlikely that the Thioalkalivibrio found in Mono Lake are identical to T. nitratireducens. We found that $86 \%$ of all transcripts assigned to Thioalkalivibrio had hits in the $T$. nitratireducens genome. The average inferred amino acid identity of the transcripts to proteins from T. nitratireducens was $78 \%$, which corresponds approximately to the genus level (Luo et al., 2014).

We used differential transcription analysis to look for genes that might be transcribed more at one depth than another. Transcription of genes most similar to those in the T. nitratireducens genome at 10, 18, 25 and $31 \mathrm{~m}$ was compared to transcription at $15 \mathrm{~m}$, 


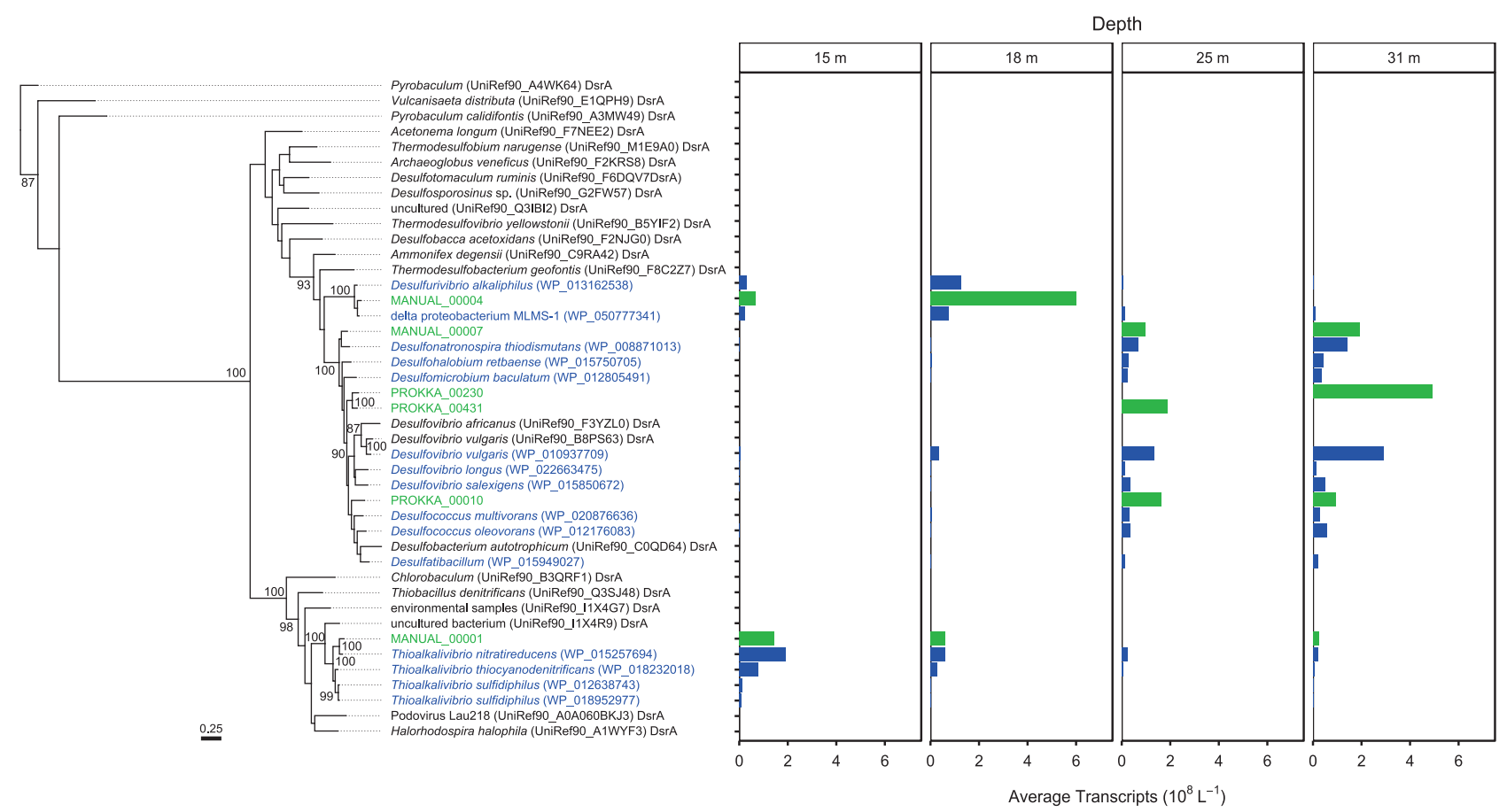

Figure 5 Maximum likelihood tree of reference dissimilatory sulfite reductase (DsrA) proteins along with proteins found in reference genomes and representative (90\% identity cluster) inferred amino acid sequences of open reading frames found in contigs assembled from Mono Lake transcripts (green). Hits to reference proteins (blue) are indicated by organism and RefSeq accession number. Nodes labeled with 'DsrA' are sequences from the reference database. Pyrobaculum DsrA was used as the outgroup. The LG+I+G model was used and bootstrap support (100 replicates) $>75 \%$ is shown.

arbitrarily chosen as a reference depth for comparison purposes. The top 20 statistically significant (adjusted $P$-value $<0.05)$ differentially transcribed genes for each depth relative to $15 \mathrm{~m}$ are listed in Supplementary Table S3.

Transcription of genes known to be involved in sulfur and arsenic metabolism were analyzed separately (Supplementary Table S4). Transcripts of sulfite and arsenite oxidation genes ( $d s r$ and arx operons) were among those with the greatest change in transcription between 10 vs $15 \mathrm{~m}$. The genes that were the most highly transcribed at $15 \mathrm{~m}$ (relative to the other depths) include members of the dissimilatory sulfite reductase operon and proteins involved in electron transport and respiration, indicating respiration of sulfite at $15 \mathrm{~m}$. In addition, differential transcription analysis of inferred arsenate reductase and arsenite oxidase genes show that arsenite oxidase and arsenate reductase operons are both more highly transcribed at $15 \mathrm{~m}$ relative to other depths.

\section{Discussion}

Overview

Mono Lake is a complex geochemical system with 3 major electron acceptors (oxygen, arsenate and sulfate) and electron donors ranging from organic carbon and methane to reduced As and S compounds and ammonium (Oremland et al., 2000; Hollibaugh et al., 2005). Our results indicate that organisms involved in the metabolism of inorganic sulfur and arsenic compounds are abundant in the water column of Mono Lake, especially at $15 \mathrm{~m}$ and below. Fermentation and disproportionation reactions are also likely important, especially in anoxic bottom waters. Some of these interactions are shown in the conceptual model presented in Supplementary Figure S7, which relates the vertical distribution of potential electron donors and acceptors to microbial processes and the genes that are the focus of this study.

Some of the results were unexpected, for example, the abundance of arr $A$ transcripts in samples from depths in the lake where no arsenate is detected, and the failure to detect aio $A$ or ars genes in the surface layer of the lake. These highlights suggest that a similar analysis of transcripts characteristic of other geochemical processes, such as aspects of the $\mathrm{N}$ cycle, may reveal additional unexpected processes and relationships.

\section{CISM genes}

The most frequent hits of transcripts to reference sequences in the CISM database were to formate dehydrogenases (Figure 2). These enzymes catalyze the conversion of formate to $\mathrm{CO}_{2}$ and occur in a wide variety of organisms (Grimaldi et al., 2013). Comparison of the formate dehydrogenase sequences used in the CISM database to RefSeq returned top hits to two general types of formate dehydrogenase (data not shown). One is membrane bound and known to be 
involved in generating a proton motive force tied to electron transport driven by nitrate reductase (Jormakka et al., 2002), and the other is a formate dehydrogenase known to be associated with the formate hydrogen lyase complex (McDowall et al., 2014).

\section{Arsenic cycle transcripts}

Aerobic arsenite oxidation is mediated by AioA (Lett et al., 2012). We detected very few aio $A$ transcripts in our samples, even in oxic surface waters: 0, 0.09, $0.04,0.05$ and $0.02 \%$ of all transcripts sampled at 10 , $15,18,25$ and $31 \mathrm{~m}$, respectively; and some of the apparent aio $A$ hits may be bioinformatic artefacts. As Mono Lake surface water communities are dominated by poorly characterized Bacteriodetes and Actinobacteria (Humayoun et al., 2003), one possibility is that aioA genes (and likely others) in Mono Lake are divergent and thus not retrieved by BLAST against RefSeq.

In contrast, $\operatorname{arx} A$ accounted for to $0,48,10,7$ and $7 \%$ of the transcripts recovered for the same samples. Although transcript abundance does not necessarily correlate directly with enzyme activity, and AioA and ArxA may turnover at different rates, this distribution suggests that arsenite diffusing upward from anoxic waters is rapidly oxidized in the oxycline by an electron acceptor other than oxygen. Indeed, arsenite was not detected in the $10 \mathrm{~m}$ sample (Figure 1). These observations also suggest that arsenite production in the surface layer by the ars pathway is not significant, despite arsenate concentrations $>200 \mu \mathrm{M}$. This is borne out by the near absence of ars transcripts in the $10 \mathrm{~m}$ sample (Supplementary Figure S2). Although Mono Lake surface waters contain high concentrations of arsenate, they also contain high concentrations of phosphorus ( 570 $\mathrm{M}$, Hollibaugh, unpublished data). Assuming the $\mathrm{P}$ is primarily in the form of inorganic phosphate, the high concentration (P:As ratio of 2.85) may competitively inhibit uptake of arsenate by the lake's biota, and thus reduce their dependence on the ars detoxification pathway on the one hand, and production of arsenite on the other.

The arxA-type arsenite oxidase was found throughout the water column below $10 \mathrm{~m}$, raising the question of the identity of the electron acceptor for arsenite oxidation at depth in the lake. The water below the pycnocline is sulfidic and devoid of oxygen (Figure 1) and there is no evidence of springs near the station that might supply electron acceptors (for example, oxygen or nitrate) via groundwater. The sampling station is kilometers from the edges of the lake where edge-mixing might enhanced the flux of electron acceptors across the pycnocline (MacIntyre et al., 1999; Vidal et al., 2013). The water column of the lake was stably stratified at depth so downward transport of active cells from the pycnocline by mixing seems unlikely. Similarly, it seems unlikely that a flux of sinking cells could support this distribution of transcripts.
So far, $\operatorname{arx} A$ has only been found in anaerobes (Zargar et al., 2012; van Lis et al., 2013) growing chemoautotrophically with electron acceptors such as nitrate and $\mathrm{Fe}(\mathrm{III})$, yet $\operatorname{arxA}$ was the most abundant arsenic cycle transcript encountered under microaerophilic conditions at $15 \mathrm{~m}$ (Figure 2). The taxonomic affiliations of most of the $\operatorname{arx} A$ hits were to Thioalkalivibrio and Halomonas species. We have no direct evidence from this study that Thioalkalivibrio is able to oxidize arsenite, but two other relatives in the Ectothiorhodospiraceae family, Ectothiorhodospira sp. PHS-1 (Kulp et al., 2008) and Alkalilimnicola ehrlichii MLHE-1 (Hoeft et al., 2007) both oxidize arsenite and transcribe the arx $A$ gene (Zargar et al., 2010, 2012). Arsenite was oxidized photoautotrophically by an Ectothiorhodospira-dominated enrichment culture raised from a Mono Lake inoculum (Budinoff and Hollibaugh, 2008). Photoautotrophic arsenite oxidation by Ectothiorhodospira sp. PHS-1 has been shown to depend on arxA (Hernandez-Maldonado et al., 2017), and three other Ectothiorhodospira strains containing the $\operatorname{arx} A$ gene have been shown to oxidize arsenite photoautotrophically (Hoeft McCann et al., 2017). It is likely that there was sufficient irradiance at $15 \mathrm{~m}$ when we sampled to have supported anoxygenic photosynthesis. Halomonas species from Big Soda Lake, NV (a lake with chemistry similar to Mono Lake) have been shown to oxidize arsenite and to contain arxA (A. Conrad, unpublished thesis) and an arsenite-oxidizing, $\operatorname{arx} A$ containing strain related to Halomonas (designated ANAO-440) has been isolated from a Mongolian soda lake (Hamamura et al., 2014). Thus, Halomonas and Thioalkalivibrio strains appear to be important members of the arsenite-oxidizing community in Mono Lake.

Transcripts of arsenate reductase (arrA) were found throughout the water column at all depths below the oxic surface layer sampled at $10 \mathrm{~m}$. We assume that the presence of transcripts from this gene in suboxic and microaerophilic samples at 15 and $18 \mathrm{~m}$ either reflects organisms associated with particles with anoxic interiors, or possibly temporal shifts in the vertical distribution of oxygen produced by photosynthesis. The microalga Picocystis forms a dense 'plate' in the oxycline (Figure 1; Roesler et al., 2002; Humayoun et al., 2003), where hypoxia provides a refuge from grazing by Artemia. Alternatively, arrA transcription may not be inhibited under microaerophilic conditions.

In contrast to the limited taxonomic range of $\operatorname{arx} A$ transcripts (Gammaproteobacteria), transcripts related to arrA were more diverse (Supplementary Figure S2). We retrieved arrA transcripts from a number of bacterial and archaeal genera including Desulfurispirillum, Desulfitobacterium, Desulfosporosinus, Aeromonas, Ferrimonas and Thioalkalivibrio. Strains of those genera have been shown directly (Niggemyer et al., 2001; Pérez-Jiménez et al., 2005; Nakagawa et al., 2006; Rauschenbach 
et al., 2012) or indirectly (Pepi et al., 2007) to be able to reduce arsenate. Six different $\operatorname{arr} A$ clades each had $>10 \%$ relative abundance at $15-31 \mathrm{~m}$ : Thioalkalivibrio nitratireducens, Desulfurispirillum indicum, Desulfovibrio alkalitolerans, Natronobacterium gregoryi, Alkaliphilus oremlandii and Natranaerobius thermophilus (Figure 4). Of these, only Alkaliphilus oremlandii and Desulfurispirillum indicum have been shown to reduce arsenate (Fisher et al., 2008a; Rauschenbach et al., 2012). An arsenate-reducing haloarchaeal biofilm community containing an ArrA operon most similar to Natronobacterium gregoryi has been described (Rascovan et al., 2016) and we detected an haloarchaeal arsenate reductase most similar to a gene from Halobiforma sp. in our samples. To our knowledge none of the other organisms that our analysis suggests may contain arr $A$ have been tested for their ability to use arsenate as an electron acceptor.

\section{Sulfur cycle transcripts}

Microbial oxidation of sulfur compounds (sulfide, sulfite, thiosulfate and elemental sulfur) is performed by both phototrophic and lithotrophic bacteria (Friedrich et al., 2005; Frigaard and Dahl, 2008). Oxidative and reductive transformations of sulfur compounds are mediated by a large number of enzymes, but recent molecular surveys have focused on $\operatorname{sox} B$ (thiosulfate oxidation), $\operatorname{apr} B A$ (conversion of sulfite to sulfate or the reverse through APS) and $d \operatorname{sr} A B$ (conversion of sulfite to sulfide or the reverse; Meyer et al., 2007; Meyer and Kuever, 2007b; Muller et al., 2015). This history led us to focus on these genes in our analysis. We performed a search of metatranscriptome reads against a custom database of common sulfur oxidation and sulfate reduction pathway proteins (Apr, Dsr, Sox, Sat, Sor; Supplementary Table S2), then hits to AprA, DsrA and SoxB were examined more closely (Supplementary Figures S3 and S4).

Oxidation of reduced sulfur compounds ( $\mathrm{HS}^{-}, \mathrm{S}$ (0), thiosulfate) was represented by transcripts of key genes encoding proteins of sulfur oxidation pathways (reverse DsrA and AprA, SoxB) in organisms known to oxidize sulfur compounds. More transcripts from the $15 \mathrm{~m}$ samples were assigned to SoxB, indicating thiosulfate oxidation (Meyer et al., 2007), than to AprA or DsrA. $s o x B$ transcripts from genes most closely related to Thioalkalivibrio nitratireducens, to a member of the Gammaproteobacteria family Piscirickettsiaceae, and contig PROKKA_00002 were most abundant at 15 and $18 \mathrm{~m}$, which is similar to the distribution of $\operatorname{arx} A$ transcripts from genes most similar to Thioalkalivibrio and Halomonas. In contrast, transcripts most similar to $s o x B$ genes from Thioalkalimicrobium cyclicum and contig PROKKA_00004 were abundant throughout the anoxic water column, suggesting different functions for this protein in these two clades. Although the genes in both organisms are annotated as $\operatorname{sox} B$, they only shared $46 \%$ amino acid identity. The soxB in Thioalkalimicrobium and other related non-Chromatiales Gammaproteobacteria is found in a conserved gene cluster, while the $s_{0 x} B$ gene in Thioalkalivibrio is not in this cluster.

Thioalkalivibrio and Thioalkalimicrobium were two of the most transcriptionally active prokaryotes in Mono Lake (Figure 2). Representative species Thioalkalivibrio jannaschii and Thioalkalimicrobium cyclicum have been isolated from Mono Lake (Sorokin et al., 2002). Their abundance in Mono Lake is consistent with findings from other soda lake environments (Sorokin et al., 2007, 2011). Growth studies indicate that these species are aerobic or perhaps prefer microaerophilic conditions (Sorokin et al., 2002), thus the abundance and diversity of transcripts from the sample at the bottom of the oxycline $(15 \mathrm{~m})$ is to be expected. The presence of a large number of $\operatorname{sox} B$ transcripts affiliated with Thioalkalimicrobium and contig PROKKA_00004 in samples from anoxic depths (18-25 m) suggests thiosulfate oxidation coupled to an alternative electron acceptor, or possibly disproportionation of thiosulfate, although no Gammaproteobacteria have been shown to perform this process (Finster, 2008; Poser et al., 2013). An alternative is oxidation and/or disproportionation of thioarsenic compounds mediated by SoxB (Edwardson et al., 2014); however, oxidation would still require an electron acceptor (Tourova et al., 2013).

An additional indication of the significance of sulfide oxidation at $18 \mathrm{~m}$ is the abundance of transcripts for DsrA and AprA associated with Desulfobulbaceae (Strain MLMS-1 and Desulfurivibrio alkaliphilus). Although these organisms fall into 'sulfate reducing' groups based on their DsrA phylogeny (Muller et al., 2015), MLMS-1 is known to oxidize sulfide with arsenate as the electron acceptor (Hoeft et al., 2004; Hollibaugh et al., 2006) as well as disproportionate thioarsenate compounds (Planer-Friedrich et al., 2015). Sulfide oxidation coupled to arsenate reduction has been shown to be mediated by Desulfobulbaceae in enrichment cultures from Mono Lake (Hollibaugh et al., 2006). Desulfurivibrio alkaliphilus is unable to reduce sulfate (Sorokin et al., 2008) but reduces (or disproportionates) thiosulfate and performs disproportionation of elemental sulfur and polysulfides (Poser et al., 2013).

Sulfate reduction in Mono Lake appears to be dominated by Deltaproteobacteria that are members of the order Desulfovibrionales (Figure 4,Supplementary Figures S4-S9). This conclusion is consistent with previous studies of the distribution of sulfur-reducing bacteria in Mono Lake by Scholten et al., (2005). This study of the distribution of diagnostic 16S rRNA genes found that sulfate-reducing bacteria were abundant in the anoxic depths of the lake; although they were not able to corroborate this finding with markers based on functional genes ( $d s r A B$ and $\operatorname{apr} A)$. A previous study of sulfate and arsenate reduction rates in the Mono Lake 
water column hypothesized that arsenate and sulfate reduction were occurring simultaneously or that there was a potential shift in SRB activity between sulfate and arsenate reduction (Oremland et al., 2000). We found transcripts most similar to genes from Desulfovibrio and Desulfonatronospira indicating arsenate (arrA) and sulfate reduction ( $d s r B$ and $a p r A)$ in the same sample. Therefore, it is plausible that these organisms are capable of performing sulfate and arsenate reduction simultaneously.

\section{Depth distribution of transcripts related to \\ Thioalkalivibrio}

Our analysis of differential transcription of genes most similar to those in Thioalkalivibrio genomes showed that sulfur and arsenic cycle genes are transcribed significantly more than expected at $15 \mathrm{~m}$ relative to other depths. This reinforces conclusions from transcript counts and indicates that arsenite and sulfite oxidation are both important to Thioalkalivibrio at $15 \mathrm{~m}$. Additional Thioalkalivibrio genes that were more highly transcribed at $15 \mathrm{~m}$ relative to other depths were related to growth (ribosomal proteins and ATP production), respiration and electron transport (ubiquinone and cytochrome), and carbon assimilation (RuBisCO). Based on this evidence, we hypothesize that Thioalkalivibrio-like organisms are growing and/or respiring more rapidly at $15 \mathrm{~m}$ than at other depths. Twelve of the 28 genes that were transcribed more strongly at $18-31 \mathrm{~m}$ than at $15 \mathrm{~m}$ were annotated as hypothetical proteins, although predictions of their functions can be made by conserved domain analysis (see Supplementary Table S4). Although Thioalkalivibrio-like genes are transcribed at $18-31 \mathrm{~m}$, a suitable electron acceptor (oxygen, nitrate or potentially arsenate) may not be available and thus the cells may not be able to respire or grow.

The use of a custom database to identify ambiguously annotated CISM family genes revealed transcripts for putative ArxA and ArrA proteins in organisms for which pathways for arsenic transformations have not been identified. However, phylogenetic analysis of these protein sequences clearly place them in groups of prokaryotes known to contain arsenate reductases and arsenite oxidases. Our analysis has thus revealed greater diversity of organisms involved in arsenic cycling in Mono Lake, and presumably in other similar habitats, than has been realized previously. In addition, transformations of both sulfur and arsenic compounds appear in some cases to be mediated by the same organisms. These results highlight the complex interplay between the arsenic and sulfur geochemical cycles in Mono Lake.

\section{Conflict of Interest}

The authors declare no conflict of interest.

\section{Acknowledgements}

We thank Meredith Ross, Christopher Abin, Ron Oremland and Larry Miller at USGS, the staff of the Sierra Nevada Aquatic Research Lab and Tom Crowe of Mono Lake Boat Tours for field support. Ron Oremland, Larry Miller and three anonymous reviewers provided insightful comments on an earlier draft of this manuscript. We thank Britta PlanerFriedrich for analyzing samples for arsenic and thioarsenic speciation. We thank Brandon Satinsky for internal mRNA standards, Shalabh Sharma, and the Georgia Advanced Computing Resource Center at UGA for bioinformatics support and scripts. This work was supported by the National Science Foundation Award EAR 09-52271 to JTH.

\section{References}

Altschul SF, Gish W, Miller W, Myers EW, Lipman DJ. (1990). Basic local alignment search tool. J Mol Biol 215: 403-410.

Amend JP, Saltikov C, Lu G-S, Hernandez J. (2014). Microbial arsenic metabolism and reaction energetics. Rev Mineral Geochem 79: 391-433.

Blum JS, Han S, Lanoil B, Saltikov C, Witte B, Tabita FR et al. (2009). Ecophysiology of 'Halarsenatibacter silvermanii' Strain SLAS-1T, gen. nov., sp. nov., a facultative chemoautotrophic arsenate respirer from salt-saturated Searles Lake, California. Appl Environ Microbiol 75: 1950-1960.

Budinoff CR, Hollibaugh JT. (2008). Arsenite-dependent photoautotrophy by an Ectothiorhodospira-dominated consortium. ISME J 2: 340-343.

Canfield DE, Stewart FJ, Thamdrup B, De Brabandere L, Dalsgaard T, Delong EF et al. (2010). A cryptic sulfur cycle in oxygen-minimum-zone waters off the Chilean coast. Science 330: 1375-1378.

Denton K, Atkinson M, Borenstein S, Carlson A, Carroll T, Cullity $\mathrm{K}$ et al. (2013). Identification of a possible respiratory arsenate reductase in Denitrovibrio acetiphilus, a member of the phylum Deferribacteres. Arch Microbiol 195: 661-670.

Edwardson CF, Planer-Friedrich B, Hollibaugh JT. (2014). Transformation of monothioarsenate by haloalkaliphilic, anoxygenic photosynthetic purple sulfur bacteria. FEMS Microbiol Ecol 90: 858-868.

Finster K. (2008). Microbiological disproportionation of inorganic sulfur compounds. J Sulfur Chem 29: 281-292.

Fisher E, Dawson AM, Polshyna G, Lisak J, Crable B, Perera E et al. (2008a). Transformation of inorganic and organic arsenic by Alkaliphilus oremlandii sp. nov. strain OhILAs. Ann N Y Acad Sci 1125: 230-241.

Fisher JC, Wallschlager D, Planer-Friedrich B, Hollibaugh JT. (2008b). A new role for sulfur in arsenic cycling. Environ Sci Technol 42: 81-85.

Friedrich CG, Bardischewsky F, Rother D, Quentmeier A, Fischer J. (2005). Prokaryotic sulfur oxidation. Curr Opin Microbiol 8: 253-259.

Frigaard N-U, Dahl C. (2008). Sulfur metabolism in phototrophic sulfur bacteria. Adv Microb Physiol 54: 103-200.

Fu H-L, Meng Y, Ordóñez E, Villadangos AF, Bhattacharjee H, Gil JA et al. (2009). Properties of arsenite efflux permeases (Acr3) from alkaliphilus metalliredigens and Corynebacterium glutamicum. J Biol Chem 284: 19887-19895. 
Gifford SM, Sharma S, Rinta-Kanto JM, Moran MA. (2011). Quantitative analysis of a deeply sequenced marine microbial metatranscriptome. ISME J 5: 461-472.

Grimaldi S, Schoepp-Cothenet B, Ceccaldi P, Guigliarelli B, Magalon A. (2013). The prokaryotic Mo/W-bisPGD enzymes family: a catalytic workhorse in bioenergetic. Biochim Biophys Acta 1827: 1048-1085.

Hamamura N, Macur RE, Korf S, Ackerman G, Taylor WP, Kozubal M et al. (2009). Linking microbial oxidation of arsenic with detection and phylogenetic analysis of arsenite oxidase genes in diverse geothermal environments. Environ Microbiol 11: 421-431.

Hamamura N, Itai T, Liu Y, Reysenbach A-L, Damdinsuren N, Inskeep WP. (2014). Identification of anaerobic arsenite-oxidizing and arsenate-reducing bacteria associated with an alkaline saline lake in Khovsgol, Mongolia. Environ Microbiol Rep 6: 476-482.

Hernandez-Maldonado J, Sanchez-Sedillo B, Stoneburner B, Boren A, Miller L, McCann S et al. (2017). The genetic basis of anoxygenic photosynthetic arsenite oxidation. Environ Microbiol 19: 130-141.

Hilton JA, Satinsky BM, Doherty M, Zielinski B, Zehr JP. (2015). Metatranscriptomics of $\mathrm{N}_{2}$-fixing cyanobacteria in the Amazon River plume. ISME J 9: 1557-1569.

Hoeft McCann S, Boren A, Hernandez-Maldonado J, Stoneburner B, Saltikov C, Stolz J et al. (2017). Arsenite as an electron donor for anoxygenic photosynthesis: Description of three strains of Ectothiorhodospira from Mono Lake, California and Big Soda Lake, Nevada. Life 7: 1 .

Hoeft SE, Kulp TR, Stolz JF, Hollibaugh JT, Oremland RS. (2004). Dissimilatory arsenate reduction with sulfide as electron donor: Experiments with mono lake water and isolation of Strain MLMS-1, a chemoautotrophic arsenate respirer. Appl Environ Microbiol 70 2741-2747.

Hoeft SE, Blum JS, Stolz JF, Tabita FR, Witte B, King GM et al. (2007). Alkalilimnicola ehrlichii sp. nov., a novel, arsenite-oxidizing haloalkaliphilic gammaproteobacterium capable of chemoautotrophic or heterotrophic growth with nitrate or oxygen as the electron acceptor. Int J Syst Evol Microbiol 57: 504-512.

Hollibaugh J, Carini S, Gurleyuk H, Jellison R, Joye S, Lecleir G et al. (2005). Arsenic speciation in Mono Lake, California: response to seasonal stratification and anoxia. Geochim Cosmochim Acta 69: 1925-1937.

Hollibaugh JT, Budinoff C, Hollibaugh RA, Ransom B, Bano N. (2006). Sulfide oxidation coupled to arsenate reduction by a diverse microbial community in a soda lake. Appl Environ Microbiol 72: 2043-2049.

Hollibaugh JT, Gifford SM, Moran MA, Ross MJ, Sharma S, Tolar BB. (2014). Seasonal variation in the metratranscriptomes of a Thaumarchaeota population from SE USA coastal waters. ISME J 8: 685-698.

Humayoun SB, Bano N, Hollibaugh JT. (2003). Depth distribution of microbial diversity in Mono Lake, a meromictic soda lake in California. Appl Environ Microbiol 69: 1030-1042.

Inskeep WP, Macur RE, Hamamura N, Warelow TP, Ward SA, Santini JM. (2007). Detection, diversity and expression of aerobic bacterial arsenite oxidase genes. Environ Microbiol 9: 934-943.

Jellison R, Melack JM. (1993). Algal photsynthetic activity and its response to meromixis in hypersaline Mono Lake, California. Limnol Oceanogr 38: 818-837.
Jormakka M, Tornroth S, Byrne B, Iwata S. (2002). Molecular basis of proton motive force generation: structure of formate dehydrogenase-N. Science 295: 1863-1868.

Kalanetra KM, Bano N, Hollibaugh JT. (2009). Ammoniaoxidizing Archaea in the Arctic Ocean and Antarctic coastal waters. Environ Microbiol 11: 2434-2445.

Kearse M, Moir R, Wilson A, Stones-Havas S, Cheung M, Sturrock S et al. (2012). Geneious Basic: an integrated and extendable desktop software platform for the organization and analysis of sequence data. Bioinformatics 28: 1647-1649.

Kelly DP, Shergill JK, Lu WP, Wood AP. (1997). Oxidative metabolism of inorganic sulfur compounds by bacteria. Antonie Van Leeuwenhoek 71: 95-107.

Kulp TR, Hoeft SE, Miller LG, Saltikov C, Murphy JN, Han S et al. (2006). Dissimilatory arsenate and sulfate reduction in sediments of two hypersaline, arsenicrich soda lakes: Mono and Searles lakes, California. Appl Environ Microbiol 72: 6514-6526.

Kulp TR, Hoeft SE, Asao M, Madigan MT, Hollibaugh JT, Fisher JC et al. (2008). Arsenic(III) fuels anoxygenic photosynthesis in hot spring biofilms from Mono Lake, California. Science 321: 967-970.

Lengke MF, Sanpawanitchakit C, Tempel RN. (2009). The oxidation and dissolution of arsenic-bearing sulfides. Can Mineral 47: 593-613.

Lett MC, Muller D, Lievremont D, Silver S, Santini J. (2012). Unified nomenclature for genes involved in prokaryotic aerobic arsenite oxidation. J Bacteriol 194: 207-208.

Li W, Godzik A. (2006). Cd-hit: a fast program for clustering and comparing large sets of protein or nucleotide sequences. Bioinformatics 22: 1658-1659.

Loy A, Duller S, Baranyi C, Mussmann M, Ott J, Sharon I et al. (2009). Reverse dissimilatory sulfite reductase as phylogenetic marker for a subgroup of sulfur-oxidizing prokaryotes. Environ Microbiol 11: 289-299.

Luo C, Rodriguez-R LM, Konstantinidis KT. (2014). MyTaxa: an advanced taxonomic classifier for genomic and metagenomic sequences. Nucleic Acids Res 42: e73.

MacIntyre S, Flynn KM, Jellison R, Romero JR. (1999). Boundary mixing and nutrient fluxes in Mono Lake, California. Limnol Oceanogr 44: 512-529.

Malasarn D, Saltikov W, Campbell KM, Santini JM, Hering JG, Newman DK. (2004). arrA is a reliable marker for As(V) respiration. Science 306: 455-455.

McDowall JS, Murphy BJ, Haumann M, Palmer T, Armstrong FA, Sargent F. (2014). Bacterial formate hydrogen lyase complex. Proc Natl Acad Sci USA 111: E3948-E3956.

Mesbah NM, Hedrick DB, Peacock AD, Rohde M, Wiegel J. (2007). Natranaerobius thermophilus gen. nov., sp. nov., a halophilic, alkalithermophilic bacterium from soda lakes of the Wadi An Natrun, Egypt, and proposal of Natranaerobiaceae fam. nov. and Natranaerobiales ord. nov. Int J Syst Evol Microbiol 57: 2507-2512.

Meyer B, Imhoff JF, Kuever J. (2007). Molecular analysis of the distribution and phylogeny of the $s o x B$ gene among sulfur-oxidizing bacteria-evolution of the Sox sulfur oxidation enzyme system. Environ Microbiol 9: 2957-2977.

Meyer B, Kuever J. (2007a). Molecular analysis of the distribution and phylogeny of dissimilatory adenosine5 '-phosphosulfate reductase-encoding genes (aprBA) 
among sulfur-oxidizing prokaryotes. Microbiology 153: 3478-3498.

Meyer B, Kuever J. (2007b). Molecular analysis of the diversity of sulfate-reducing and sulfur-oxidizing prokaryotes in the environment, using aprA as functional marker gene. Appl Environ Microbiol 73: 7664-7679.

Meyer B, Kuever J. (2007c). Phylogeny of the alpha and beta subunits of the dissimilatory adenosine5'-phosphosulfate (APS) reductase from sulfatereducing prokaryotes-origin and evolution of the dissimilatory sulfate-reduction pathway. Microbiology 153: 2026-2044.

Mori Y, Purdy KJ, Oakley BB, Kondo R. (2010). Comprehensive detection of phototrophic sulfur bacteria using PCR primers that target reverse dissimilatory sulfite reductase gene. Microbes Environ 25: 190-196.

Muller AL, Kjeldsen KU, Rattei T, Pester M, Loy A. (2015). Phylogenetic and environmental diversity of DsrABtype dissimilatory (bi)sulfite reductases. ISME J 9: 1152-1165.

Muyzer G, Stams AJ. (2008). The ecology and biotechnology of sulphate-reducing bacteria. Nat Rev Microbiol 6: $441-454$

Nakagawa T, Iino T, Suzuki K-I, Harayama S. (2006). Ferrimonas futtsuensis sp. nov. and Ferrimonas kyonanensis sp. nov., selenate-reducing bacteria belonging to the Gammaproteobacteria isolated from Tokyo Bay. Int J Syst Evol Microbiol 56: 2639-2645.

Niggemyer A, Spring S, Stackebrandt E, Rosenzweig RF. (2001). Isolation and characterization of a novel As(V)reducing bacterium: implications for arsenic mobilization and the genus desulfitobacterium. Appl Environ Microbiol 67: 5568-5580.

Oremland RS, Dowdle PR, Hoeft S, Sharp JO, Schaefer JK, Miller LG et al. (2000). Bacterial dissimilatory reduction of arsenate and sulfate in meromictic Mono Lake, California. Geochim Cosmochim Acta 64: 3073-3084.

Oremland RS, Hoeft SE, Santini JM, Bano N, Hollibaugh RA, Hollibaugh JT. (2002). Anaerobic oxidation of arsenite in Mono Lake water and by a facultative, arsenite-oxidizing chemoautotroph, Strain MLHE-1. Appl Environ Microbiol 68: 4795-4802.

Oremland RS, Stolz JF. (2003). The ecology of arsenic. Science 300: 939-944.

Pepi M, Volterrani M, Renzi M, Marvasi M, Gasperini S, Franchi E et al. (2007). Arsenic-resistant bacteria isolated from contaminated sediments of the Orbetello Lagoon, Italy, and their characterization. I Appl Microbiol 103: 2299-2308.

Pérez-Jiménez JR, DeFraia C, Young LY. (2005). Arsenate respiratory reductase gene (arrA) for Desulfosporosinus sp. strain Y5. Biochem Biophys Res Commun 338: 825-829.

Pfeffer C, Larsen S, Song J, Dong M, Besenbacher F, Meyer RL et al. (2012). Filamentous bacteria transport electrons over centimetre distances. Nature 491: 218-221.

Planer-Friedrich B, London J, McCleskey RB, Nordstrom DK, Wallschlager D. (2007). Thioarsenates in geothermal waters of Yellowstone National Park: Determination, preservation, and geochemical importance. Environ Sci Technol 41: 5245-5251.

Planer-Friedrich B, Fisher J, Hollibaugh J, Suess E, Wallschlager D. (2009). Oxidative transformation of trithioarsenate along alkaline geothermal drainagesabiotic versus microbially mediated processes. Geomicrobiol J 26: 339-350.
Planer-Friedrich B, Suess E, Scheinost AC, Wallschlager D. (2010). Arsenic speciation in sulfidic waters: reconciling contradictory spectroscopic and chromatographic evidence. Anal Chem 82: 10228-10235.

Planer-Friedrich B, Hartig C, Lohmayer R, Suess E, McCann SH, Oremland R. (2015). Anaerobic chemolithotrophic growth of the haloalkaliphilic bacterium Strain MLMS-1 by disproportionation of monothioarsenate. Environ Sci Technol 49: 6554-6563.

Poretsky RS, Sun S, Mou X, Moran MA. (2010). Transporter genes expressed by coastal bacterioplankton in response to dissolved organic carbon. Environ Microbiol 12: 616-627.

Poser A, Lohmayer R, Vogt C, Knoeller K, Planer-Friedrich B, Sorokin D et al. (2013). Disproportionation of elemental sulfur by haloalkaliphilic bacteria from soda lakes. Extremophiles 17: 1003-1012.

Rascovan N, Maldonado J, Vazquez MP, Eugenia Farias M. (2016). Metagenomic study of red biofilms from Diamante Lake reveals ancient arsenic bioenergetics in haloarchaea. ISME J 10: 299-309.

Rauschenbach I, Bini E, Häggblom MM, Yee N. (2012). Physiological response of Desulfurispirillum indicum S5 to arsenate and nitrate as terminal electron acceptors. FEMS Microbiol Ecol 81: 156-162.

Roesler CS, Culbertson CW, Etheridge SM, Goericke R, Kiene RP, Miller LG et al. (2002). Distribution, production, and ecophysiology of Picocystis strain ML in Mono Lake, California. Limnol Oceanogr 47: $440-452$.

Rosen BP. (2002). Biochemistry of arsenic detoxification. FEBS Lett 529: 86-92.

Rothery RA, Workun GJ, Weiner JH. (2008). The prokaryotic complex iron-sulfur molybdoenzyme family. Biochim Biophys Acta 1778: 1897-1929.

Saltikov CW, Newman DK. (2003). Genetic identification of a respiratory arsenate reductase. Proc Natl Acad Sci USA 100: 10983-10988.

Satinsky BM, Gifford SM, Crump BC, Moran MA. (2013). Use of internal standards for quantitative metatranscriptome and metagenome analysis. In: Edward FD (ed), Methods in Enzymology. Academic Press: Oxford, UK, pp 237-250.

Satinsky BM, Crump BC, Smith CB, Sharma S, Zielinski BL, Doherty $\mathrm{M}$ et al. (2014). Microspatial gene expression patterns in the Amazon River plume. Proc Natl Acad Sci USA 111: 11085-11090.

Schoepp-Cothenet B, van Lis R, Philippot P, Magalon A, Russell MJ, Nitschke W. (2012). The ineluctable requirement for the trans-iron elements molybdenum and/or tungsten in the origin of life. Sci Rep 2: 263.

Scholten JCM, Joye SB, Hollibaugh JT, Murrell JC. (2005). Molecular analysis of the sulfate reducing and archaeal community in a meromictic soda lake (Mono Lake, California) by targeting $16 \mathrm{~S}$ rRNA, $\operatorname{mcr} A$, aps $A$, and dsrAB Genes. Microb Ecol 50: 29-39.

Silver S, Phung LT. (2005). Genes and enzymes involved in bacterial oxidation and reduction of inorganic arsenic. Appl Environ Microbiol 71: 599-608.

Sorokin DY, Gorlenko VM, Tourova TP, Tsapin A, Nealson KH, Kuenen GJ. (2002). Thioalkalimicrobium cyclicum sp. nov. and Thioalkalivibrio jannaschii sp. nov., novel species of haloalkaliphilic, obligately chemolithoautotrophic sulfur-oxidizing bacteria from hypersaline alkaline Mono Lake (California). Int J Syst Evol Microbiol 52: 913-920. 
Sorokin DY, Foti M, Pinkart HC, Muyzer G. (2007). Sulfuroxidizing bacteria in Soap Lake (Washington State), a meromictic, haloalkaline Lake with an unprecedented high sulfide content. Appl Environ Microbiol 73: 451-455.

Sorokin DY, Tourova TP, Mußmann M, Muyzer G. (2008). Dethiobacter alkaliphilus gen. nov. sp. nov., and Desulfurivibrio alkaliphilus gen. nov. sp. nov.: two novel representatives of reductive sulfur cycle from soda lakes. Extremophiles 12: 431-439.

Sorokin DY, Kuenen JG, Muyzer G. (2011). The microbial sulfur cycle at extremely haloalkaline conditions of soda lakes. Front Microbiol 2: 44.

Sorokin DY, Banciu HL, Muyzer G. (2015). Functional microbiology of soda lakes. Curr Opin Microbiol 25: 88-96.

Stewart F, Dmytrenko O, DeLong E, Cavanaugh C. (2011). Metatranscriptomic analysis of sulfur oxidation genes in the endosymbiont of Solemya velum. Front Microbiol 2: 134.

Stewart FJ, Ottesen EA, DeLong EF. (2010). Development and quantitative analyses of a universal rRNAsubtraction protocol for microbial metatranscriptomics. ISME J 4: 896-907.

Suzek BE, Wang Y, Huang H, McGarvey PB, Wu CH, UniProt Consortium (2015). UniRef clusters: a comprehensive and scalable alternative for improving sequence similarity searches. Bioinformatics 31: 926-932.

Tourova TP, Slobodova NV, Bumazhkin BK, Kolganova TV, Muyzer G, Sorokin DY. (2013). Analysis of community composition of sulfur-oxidizing bacteria in hypersaline and soda lakes using $\operatorname{sox} B$ as a functional molecular marker. FEMS Microbiol Ecol 84: 280-289.

van Lis R, Nitschke W, Duval S, Schoepp-Cothenet B. (2013). Arsenics as bioenergetic substrates. Biochim Biophys Acta 1827: 176-188.
Vidal J, MacIntyre S, McPhee-Shaw EE, Shaw WJ, Monismith SG. (2013). Temporal and spatial variability of the internal wave field in a lake with complex morphometry. Limnol Oceanogr 58: 1557-1580.

Weiss S, Carapito C, Cleiss J, Koechler S, Turlin E, Coppee J-Y et al. (2009). Enhanced structural and functional genome elucidation of the arseniteoxidizing strain Herminiimonas arsenicoxydans by proteomics data. Biochimie 91: 192-203.

Zargar K, Hoeft S, Oremland R, Saltikov CW. (2010). Identification of a novel arsenite oxidase gene, $\operatorname{arx} A$, in the haloalkaliphilic, arsenite-oxidizing bacterium Alkalilimnicola ehrlichii strain MLHE-1. J Bacteriol 192: 3755-3762.

Zargar K, Conrad A, Bernick DL, Lowe TM, Stolc V, Hoeft $S$ et al. (2012). ArxA, a new clade of arsenite oxidase within the DMSO reductase family of molybdenum oxidoreductases. Environ Microbiol 14: 1635-1645.

(2) (1) $\Theta$ This work is licensed under a Creative Commons Attribution-NonCommercialNoDerivs 4.0 International License. The images or other third party material in this article are included in the article's Creative Commons license, unless indicated otherwise in the credit line; if the material is not included under the Creative Commons license, users will need to obtain permission from the license holder to reproduce the material. To view a copy of this license, visit http://creativecommons.org/ licenses/by-nc-nd/4.0/

(C) The Author(s) 2017

Supplementary Information accompanies this paper on The ISME Journal website (http://www.nature.com/ismej) 